\title{
A Patient with Severe Allergic Reaction After Chewing Linseed
}

\author{
Keten Tohumu Çiğneyen Bir Hastada Şiddetli Allerjik Reaksiyon
}

Emrah Uyanık', Mustafa Serinken', Bekir Dağ ı²

'Pamukkale Üniversitesi Tıp Fakültesi, Acil Tıp Anabilim Dalı, Denizli, Türkiye

${ }^{2}$ Yenişehir Devlet Hastanesi, Acil Servisi, Kahramanmaraş, Türkiye

\section{ABSTRACT}

In our country, linseed and oil are used for a number of different medical purposes (constipation, high cholesterol, menopause, etc.). In recent years, there have been reports of a feeling of fullness associated with increasing use among those who diet. In this case report, severe allergic reaction after chewing linseed is discussed.

Keywords: Linseed, severe allergic reaction, emergency department

Received: 20.06.2011 Accepted: 14.11.2011

\section{ÖZET}

Keten tohumu ve yağının, ülkemizde değişik amaçlarla (kabızlık, kolesterol yüksekliği, menapoz vb.) kullanımı olduğu bilinmektedir. Son yıllarda tokluk hissi verdiği gerekçesi ile diyet yapanlar arasında da kullanımı artmaktadır. Bu yazıda, keten tohumunun çiğnenmesi sonrası oluşan şiddetli bir allerjik reaksiyon olgusu tartışılmıştır.

Anahtar Kelimeler: Keten tohumu, şiddetli alerjik reaksiyon, acil servis

Geliş Tarihi: 20.06.2011 Kabul Tarihi: 14.11.2011

\section{Giriş}

Linum usitatissimum (Linseed), Linaceae ailesine ait bir bitkidir. Bitkinin tohumu halk arasında keten tohumu olarak bilinmekte$\operatorname{dir}($ Resim 1). Keten tohumu allerjisi ilk kez 1930 yılında tanımlanmıştır, ancak o zamandan beri nadir olarak bildirilmiştir. Bununla birlikte, günümüzde keten tohumunun laksatif olarak ve unlu mamüllerde kullanımındaki artıştan dolayı allerjik reaksiyonlarda da artış olacağı tahmin edilmektedir (1).

Bu yazıda, keten tohumunun çiğnenmesi ile ortaya çıktığını düşündüğümüz şiddetli bir allerjik reaksiyon olgusu tartışılmıştır.

\section{Olgu Sunumu}

Diyet yapan 32 yaşında bayan hasta, bir arkadaşının tavsiyesi üzerine keten tohumu alarak çiğnemiş. Yaklaşık 15 dakika sonra soluk almada zorluk, vücutta yaygın kızarıklık şikâyetleri ile acil servisimize başvurdu. Hastanın vital bulguları: kan basıncı $90 / 65$ mmHg, nabız: 116/dk ritmik, solunum sayısı: 38/dk. oksijen saturasyonu \%92 olarak ölçüldü. Hastada tüm vücutta yaygın ürtiker plakları, orofarinks bakısında uvula ödemi, dinlemekle her iki akciğerde ronküs mevcuttu. Anamnezinde herhangi bir sistemik hastalık ve atopi öyküsü yoktu. Keten tohumunu ilk defa çiğnediğini ifade etti. Hastaya hızlıca oksijen başlandı ve damar yolu açıldı. Bu esnada 0.5 mg adrenalin IM uygulandı. IV yoldan sıvı tedavisi ve H1+H2 bloker, kortikosteroid tedavisi başlandı. Semptomları gerilemeye başlayan hasta 10 dakika içinde rahatladı. Nefes darlığı ve ürtiker plakları kısmen azaldı. İlemde ronküsleri kaybolan ve uvula ödemi azalan hasta, yaklaşık 6 saat sonra önerilerle taburcu edildi. Hastanın tam kan sayımı ve biyokimyasal markerlerinde patolojik değere rastlanmadı.

\section{Tartışma}

Keten tohumuna bağlı olarak gelişen allerjik reaksiyonlar karın ağrısı, bulantı, diyare, yaygın ürtiker, akut dispne, burun akıntısı, hapşırma, burun tıkanıklığı, kaşıntı ve yaygın halsizlikle seyreden anafilaksi tablosu şeklinde ortaya çıkabilir. Keten tohumu aller- 


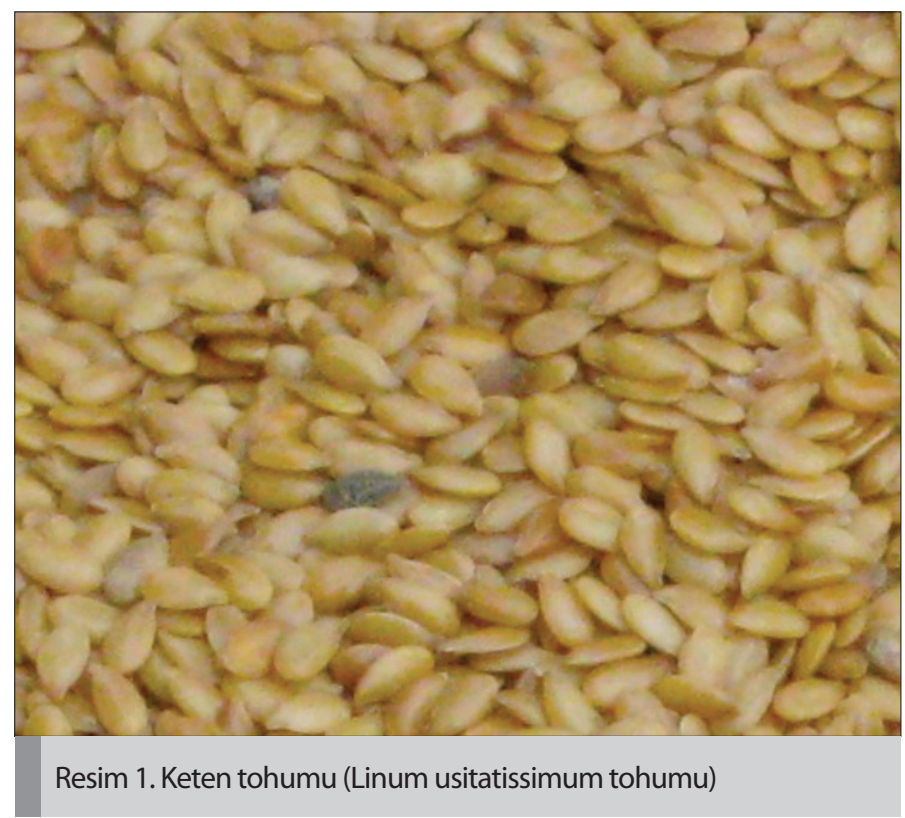

jeninin SH2 gruplarıyla bağlanmış olan 28 kDa ağırlığındaki monomerlerden oluşan bir dimer olduğu gösterilmiştir $(2,3)$.

Olgulara, keten tohumuna özgü alerjen kullanılarak yapılan PIP (prick-in-prick) testi ile kesin tanı konulabilmektedir (3). Olgumuza bu testi yapamadığımız için reaksiyonun keten tohumu kaynaklı olduğu kesin değildir. Fakat hastanın şikâyetlerinin bu alerjeni aldıktan sonra başlaması ve sonrasında kullanımı kesmesinden dolayı tekrarlamaması tanıyı kuvvetle desteklemektedir.

Keten tohumu ve yağının, ülkemizde değişik amaçlarla (kabızlık, kolesterol yüksekliği, menapoz vb.) kullanımı olduğu bilinmektedir. Son yıllarda tokluk hissi verdiği gerekçesi ile diyet yapanlar arasında da kullanımı artmaktadır (3). Ülkemizde bu alerjiye sık karşılaşılmamakla beraber bilimsel olarak yayınlanan ve bizim bulabildiğimiz tek olgu vardır. Abadoğlu (1) 2006 yılında keten tohumu çiğnenmesi ile ortaya çıkan bir olgu yayımlamıştır. Yabancı literatürde de çok fazla olmasa da keten tohumuna bağlı alerjik reaksiyon olguları mevcuttur (2-5). Fremont ve ark.'larının (2) bir çalışmasında, 1317 hastada yaptıkları PIP testi sonucu, 77'sinin (\%5.8) keten tohumu alerjisi olduğunu bildirmişlerdir. Bu 77 hastanın 72'sinin atopik olduğuda bildirilmiştir. Olgumuz da benzer şekilde atopik bünyeye sahip bir kişi olmayıp allerjenle ilk defa karşılaştığında reaksiyon oluşturduğu düşünülmüştür.

Keten tohumuna bağlı olarak gelişen allerjik reaksiyonlarda hastalarda oluşabilecek semptomlar bir özellik göstermez. Diğer olgularda olduğu gibi karın ağrısı, bulantı, diyare, yaygın ürtiker, akut dispne, burun akıntısı, hapşırma, burun tıkanıklığı, kaşıntı ve yaygın halsizlikle seyreden anafilâksi tablosu şeklinde ortaya çıkabilir. Olgumuzda tüm vücutta yaygın ürtiker plakları, uvula ödemi, dinlemekle her iki akciğerde ronküs görülmüştür.

\section{Sonuç}

Bitkisel ilaç kullanımı son yıllarda çeşitli hastalıkların tedavisi amacıyla giderek popüler olmakta, bununla birlikte yan etkilerine bağlı bilimsel yayınlarda artış gözlenmektedir. Yaygınlaşan bitkisel tedaviler, acil servis hekimlerini ciddi yan etkilerle karşı karşıya bırakabilir. Tüketicileri yan etkilerine dair bilgilendirecek bir formül bulunmalıdır.

\section{Çıkar Çatışması}

Yazarlar herhangi bir çıkar çatışması bildirmemişlerdir.

\section{Kaynaklar}

1. Abadoglu Ö. Keten Tohumu ve Allerjik Reaksiyonlar: Bir Olgu Sunumu. Astım Allerji İmmünoloji 2006; 4: 24-5.

2. Fremont S, Moneret-Vautrin DA, Franck P, Morisset M, Croizier A, Codreanu F, et al. Prospective study of sensitization and food allergy to flaxseed in 1317 subjects. Eur Ann Allergy Clin Immunol 2010; 42: 103-11.

3. Leon F, Rodriguez M, Cuevas M. Anaphylaxis to linum. Allergol Immunopathol 2003; 31: 47-9. [Crossref]

4. Lezaun A, Fraj J, Colás C, Duce F, Domínguez MA, Cuevas M, et al. Anaphylaxis from linseed. Allergy 1998; 53: 105-6. [Crossref]

5. Alonso L, Marcos ML, Blanco JG, Navarro JA, Juste S, del Mar Garcés M, et al. Anaphylaxis caused by linseed (flaxseed) intake. J Allergy Clin Immunol 1996; 98: 469-70. [Crossref] 